\title{
A recombinase polymerase amplification-lateral flow dipstick assay for rapid detection of the quarantine citrus pathogen in China, Phytophthora hibernalis
}

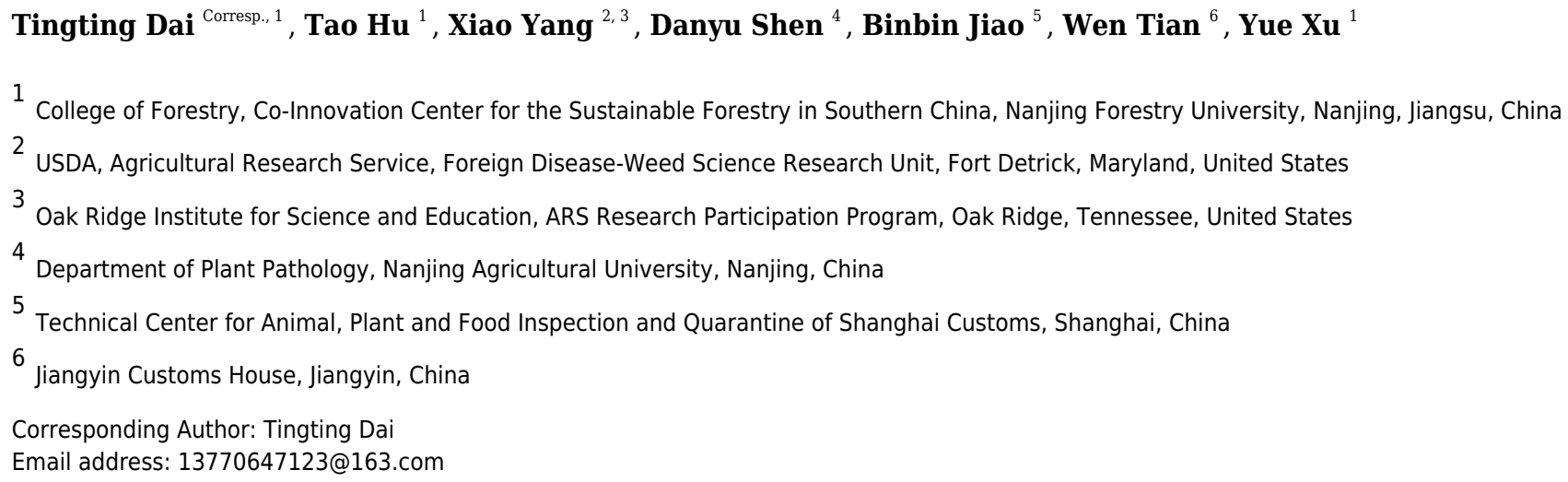

Phytophthora hibernalis, the causal agent of brown rot of citrus fruit, is an important worldwide pathogen and a quarantine pest in China. Current diagnosis of the disease relies on disease symptoms, pathogen isolation, and identification by DNA sequencing. However, symptoms caused by $P$. hibernalis can be confused with those by other Phytophthora and fungal species. Moreover, pathogen isolation, PCR amplification, and sequencing are timeconsuming. In this study, a rapid assay including 20-min recombinase polymerase amplification targeting the Ypt1 gene and 5-min visualization using lateral flow dipsticks was developed for detecting $P$. hibernalis. This assay was able to detect $0.2 \mathrm{ng}$ of $P$. hibernalis genomic DNA in a $50-\mu \mathrm{L}$ reaction system. It was specific to $P$. hibernalis without detection of other tested species including $P$. citrophthora, $P$. nicotianae, $P$. palmivora, and $P$. syringae, four other important citrus pathogens. Using this assay, $P$. hibernalis was also detected from artificially inoculated orange fruits. Results in this study indicated that this assay has the potential application to detect $P$. hibernalis at diagnostic laboratories, and plant quarantine departments of customs, especially under time- and resource-limited conditions. 


\section{A recombinase polymerase amplification-lateral flow}

\section{2 dipstick assay for rapid detection of the quarantine citrus}

\section{3 pathogen in China, Phytophthora hibernalis}

4 Tingting $\mathrm{Dai}^{1^{*}}$, Tao $\mathrm{Hu}^{1}$, Xiao Yang ${ }^{2,3}$, Danyu Shen ${ }^{4}$, Binbin Jiao ${ }^{5}$, Wen Tian ${ }^{6}$, Yue $\mathrm{Xu}^{1}$

$5{ }^{1}$ College of Forestry, Co-Innovation Center for the Sustainable Forestry in Southern China,

6 Nanjing Forestry University, Nanjing, Jiangsu, China

$7 \quad{ }^{2}$ USDA, Agricultural Research Service, Foreign Disease-Weed Science Research Unit, Fort

8 Detrick, Maryland, USA

$9 \quad{ }^{3}$ Oak Ridge Institute for Science and Education, ARS Research Participation Program, Oak

10 Ridge, Tennessee, USA

$11{ }^{4}$ Department of Plant Pathology, Nanjing Agricultural University, Nanjing, Jiangsu, China

$12{ }^{5}$ Technical Center for Animal, Plant and Food Inspection and Quarantine of Shanghai Customs,

13 Shanghai, China

$14 \quad{ }^{6}$ Jiangyin Customs House, Jiangyin, Jiangsu, China

$16{ }^{*}$ Corresponding Author:

17 Tingting Dai

Email address: 13770647123@163.com

\section{Abstract}

Phytophthora hibernalis, the causal agent of brown rot of citrus fruit, is an important worldwide pathogen and a quarantine pest in China. Current diagnosis of the disease relies on 
23 disease symptoms, pathogen isolation, and identification by DNA sequencing. However, 24 symptoms caused by $P$. hibernalis can be confused with those by other Phytophthora and fungal species. Moreover, pathogen isolation, PCR amplification, and sequencing are time-consuming. In this study, a rapid assay including 20-min recombinase polymerase amplification targeting the Ypt1 gene and 5-min visualization using lateral flow dipsticks was developed for detecting $P$. hibernalis. This assay was able to detect $0.2 \mathrm{ng}$ of $P$. hibernalis genomic DNA in a $50-\mu \mathrm{L}$ reaction system. It was specific to $P$. hibernalis without detection of other tested species including $P$. citrophthora, P. nicotianae, P. palmivora, and P. syringae, four other important citrus pathogens. Using this assay, $P$. hibernalis was also detected from artificially inoculated orange fruits. Results in this study indicated that this assay has the potential application to detect P. hibernalis at diagnostic laboratories, and plant quarantine departments of customs, especially under time- and resource-limited conditions.

Keywords: Oomycetes; RPA-LFD; Plant destroyers; Exclusivity; Inclusivity; Isothermal diagnostic assay

\section{Introduction}

Phytophthora hibernalis is an important pathogen causing brown rot (Erwin \& Ribeiro 1996) and gummosis (Graham \& Menge 2000) of citrus. It also occasionally causes diseases of other crops such as tomato and apple (Erwin \& Ribeiro 1996). Due to its potential impact on the horticultural industry, this exotic pathogen has been listed as a quarantine pest in China since 2007 (Li et al. 2019). In 2015, P. hibernalis was detected in citrus fruit shipments from Tulare County, California, USA to Shanghai, China, leading to a suspension of importing Californian citrus 
46 products to China from February to November 2015 (Hao et al. 2018; Jiao et al. 2017). Such

47 restrictions caused by this quarantine pathogen have caused significant losses to Californian citrus

48 farmers, and international trade and shipping companies in both export and import countries

49 (Adaskaveg \& Förster 2014; Hao et al. 2018; Jiao et al. 2017).

Successful quarantine measures are established on accurate and timely detection of pathogens. Traditionally, diagnoses include pathogen isolation and identification based on the morphological and molecular features. This process could be time-consuming. Therefore, it hardly meets the need of rapid detection at customs. With the advent of molecular technology, other faster and more cost-effective techniques including isothermal diagnostic assays have become the mainstream in rapid detection of many Phytophthora species (Miles et al. 2015) such as P. infestans (Hansen et al. 2016; Khan et al. 2017; Si Ammour et al. 2017), P. sojae (Dai et al. 2012; Dai et al. 2015; Rojas et al. 2017), P. nicotianae (Li et al. 2015), P. cinnamomi (Dai et al. 2019). A loop-mediated isothermal amplification (LAMP) assay for detecting P. hibernalis was developed by Li et al. (2019).

The recombinase polymerase amplification (RPA) is an emerging isothermal nucleic acid amplification technique for detecting plant pathogens. The RPA enzyme mixture conducts exponential amplification of the target region within the DNA template. This was accomplished by a phage-derived recombinase UvsX, which aggregates with two oligonucleotide primers to form a nucleoprotein filament and scan for single homologous target sequence of the DNA template (Piepenburg et al. 2006). A single-strand DNA-binding protein binds to the filament. A strand displacing DNA polymerase then amplifies the template (Daher et al. 2016; James \& Macdonald 2015; Piepenburg et al. 2006). RPA has several advantages compared to conventional 
DNA at constant and low temperatures (optimal range, $37-42{ }^{\circ} \mathrm{C}$ ), therefore, eliminating the requirement of thermal cyclers. Second, each RPA assay requires only a pair of oligonucleotide primers, while the LAMP technique requires 4 to 6 primers to synthesize various sizes of DNA amplicons (Notomi et al. 2000). Third, RPA amplicons can be visualized in real-time using lateral flow dipsticks (LFDs). The RPA-LFD assay requires an oligonucleotide probe in addition to the primer pair. The probe is conjugated with a fluorescein amidite (FAM) and a C3 spacer on its 5, and 3' ends, respectively, and a base analog tetrahydrofuran (THF) inserted as an internal base. Subsequently, the amplicons generated by the RPA primers and probe are visualized in the 'sandwich' assay (Ghosh et al. 2018; Hou et al. 2018).

In this study, a novel RPA assay targeting the ras-related Ypt1 gene of $P$. hibernalis was developed. Specificity of this assay was evaluated by testing against an array of oomycete and fungal species Moreover, sensitivity of this assay was compared with a conventional PCR-based method.

\section{Materials \& Methods}

\section{RPA primers and probe design}

Sequences of the Ypt1 gene of $P$. hibernalis (GenBank accession No. KJ755160) and other Phytophthora species were obtained from GenBank (Benson et al. 2018). Alignment of these sequences (Fig. S1) was carried out using Clustal W (Larkin et al. 2007). Six pairs of primers (Table S1) targeting the polymorphic regions of the Ypt1 gene were designed for P. hibernalis according to the TwistAmp ${ }^{\circledR}$ DNA Amplification Kits Assay Design Manual (https://www.twistdx.co.uk/docs/default-source/RPA-assay-design/twistamp-assay-designmanual-v2-5.pdf?sfvrsn=29). Their specificity to $P$. hibernalis was preliminarily evaluated using 
92 a collection of Phytophthora species (Table 1) in conventional PCR. A primer pair, including a

93 forward primer PhRPA-F and a reverse primer PhRPA-R was found exclusively and consistently

94 amplified the Ypt1 gene of $P$. hibernalis isolates. The reverse primer was then adjusted by

95 conjugating biotin at its 5 '-end (Table 2). A probe PhProbe (Table 2) was designed according to

96 the TwistAmp ${ }^{\circledR}$ DNA Amplification Kits Assay Design Manual. This set of primers and probe was

97 tested in RPA and subsequently used for optimizing the reaction condition and evaluating assay

98 specificity and sensitivity. Primers and probe (Table 2) were synthesized by Nanjing GenScript

99 Co. Ltd (Nanjing, China).

100 Isolate selection of Phytophthora species

101 Isolates of oomycete and fungal species used in this study are listed in Table 1.

102 Phytophthora hibernalis isolate 9099 was recovered from an imported pomelo fruit (Citrus

103 grandis) at Shanghai Export and Import Inspection and Quarantine Bureau (Jiao et al. 2017). All

104 isolates were part of collections at Department of Plant Pathology at Nanjing Agricultural

105 University and Department of Forest Protection at Nanjing Forestry University in Nanjing, China.

106 Culture conditions and DNA Extraction

107

Isolates of Phytophthora species were cultured in 10\% clarified V8 juice agar (cV8A) at

18 to $25^{\circ} \mathrm{C}$ in the dark. Mycelia of oomycete and fungal isolates were produced by growing individual isolates in $20 \%$ clarified V8 juice and potato dextrose broth, respectively, at 18 to 25

${ }^{\circ} \mathrm{C}$ for 3 to 5 days. Mycelia were harvested by filtration and then frozen at $-20{ }^{\circ} \mathrm{C}$. Genomic DNAs (gDNA) were extracted using a DNAsecure Plant Kit (Tiangen Biotech, Beijing, China). DNA

113 Technologies, Thermo Fisher Scientific, Wilmington, Delaware, USA). Nuclease-free water $114\left(\mathrm{nfH}_{2} \mathrm{O}\right.$; Thermo Fisher Scientific, Wilmington, Delaware, USA) was used to dilute gDNA 
115 extractions as needed. DNA samples were stored at $-20^{\circ} \mathrm{C}$ until use.

116

117

118

119

120

121

122

123

124

125

126

127

128

129

130

131

132

133

134

135

136

137

\section{RPA-LFD assay}

RPA amplifications were performed in $50-\mu \mathrm{L}$ reactions according to the quick guide of the TwistAmp ${ }^{\circledR}$ nfo Kit (TwistDx Ltd., Cambridge, UK). After mixing $2.1 \mu \mathrm{L}$ of each of PhRPA-F and PhRPA-R primers $(10 \mu \mathrm{M}), 0.6 \mu \mathrm{L}$ of PhProbe probe $(10 \mu \mathrm{M}), 29.5 \mu \mathrm{L}$ of rehydration buffer (supplied in the kit), and 11.2 $\mu \mathrm{L}$ of $\mathrm{nfH}_{2} \mathrm{O}$, the reagent mixture of each reaction was then added to the freeze-dried reaction pellet of TwistAmp ${ }^{\circledR}$ nfo Kit. DNA template $(2 \mu \mathrm{L})$ and $2.5 \mu \mathrm{L}$ of magnesium acetate $(280 \mathrm{mM})$ were added into the mixture. Reactions were carried out at $38{ }^{\circ} \mathrm{C}$. To determine the optimal amplification duration, reactions were performed for 5, 10, 15, 20, 25, and $30 \mathrm{~min}$. Each duration was tested three times. Each reaction included $2 \mu \mathrm{L}$ of the gDNA (10 ng per $\mu \mathrm{L}$ ) of $P$. hibernalis isolate 9099 . After amplification, $10 \mu \mathrm{L}$ of RPA product was mixed with $90 \mu \mathrm{L}$ of phosphate buffered saline with Tween 20 (PBST) running buffer then $10 \mu \mathrm{L}$ of RPA product-PBST mixture was pipetted to the sample pad of a HybriDetect 1 LFD (Milenia Biotec, Giessen, Germany). The dipstick was dipped into a tube containing $200 \mu \mathrm{L}$ of PBST for up to 5 min until a clear control line was visible. This visualization step using LFD was performed at room temperature (aver. $22^{\circ} \mathrm{C}$ ). When test and control lines were simultaneously visible, the detection result was positive. If only control line was visible, it indicated a negative detection result. After visualization, LFDs were air-dried and photographed using a Canon PowerShot SX730 HS camera.

\section{Sensitivity of RPA-LFD and PCR assays}

Ten-fold dilutions of gDNA of $P$. hibernalis isolate 9099 including 100, 10, 1, 0.1, 0.01, 0.001 and $0.0001 \mathrm{ng}$ per $\mu \mathrm{L}$ were used as templates in the RPA-LFD assay (20-min RPA). $\mathrm{nfH}_{2} \mathrm{O}$ was used in place of the DNA template as a no-template control (NTC) included in each set of 
138

139

140

141

142

143

144

145

146

147

148

149

150

151

152

153

154

155

156

157

158

159

160

reactions. This evaluation of sensitivity was performed three times.

To compare the sensitivity of the RPA-LFD assay to conventional PCR, the same 10-fold dilutions of gDNA of isolate 9099 were used in a PCR assay. Each dilution was used as the DNA template $(2 \mu \mathrm{L})$ in each $50-\mu \mathrm{L}$ PCR reaction. Each reaction also included $25 \mu \mathrm{L}$ of $2 \times$ Taq Master Mix (containing Taq DNA Polymerase, dNTP, and an optimized buffer; Vazyme Biotech, Nanjing, China), $2 \mu \mathrm{L}$ of each of PhRPA-F and PhRPA-R primers $(10 \mu \mathrm{M})$, and $19 \mu \mathrm{L}$ of $\mathrm{nfH}_{2} \mathrm{O}$. PCR reactions were completed in a SimpliAmp ${ }^{\mathrm{TM}}$ thermal cycler instrument (Model A24812, Thermo Fisher Scientific, Wilmington, Delaware, USA) following an initial denaturation step at $95^{\circ} \mathrm{C}$ for $3 \mathrm{~min}, 35 \mathrm{cycles}$ of $95^{\circ} \mathrm{C}$ for $15 \mathrm{sec}, 56^{\circ} \mathrm{C}$ (optimized) for $15 \mathrm{sec}$, and $72{ }^{\circ} \mathrm{C}$ for $15 \mathrm{sec}$, plus a final extension at $72{ }^{\circ} \mathrm{C}$ for $5 \mathrm{~min}$. Each set of PCR reactions included an NTC. PCR products were examined in $1 \%$ agarose gel electrophoresis at $120 \mathrm{~V}$ for approximately $25 \mathrm{~min}$. Agarose gel was stained by ethidium bromide and visualized on a transilluminator. The PCR assay was carried out three times.

\section{Specificity of the RPA-LFD assay}

The RPA-LFD assay was evaluated using gDNAs of 45 isolates of 39 species (Table 2).

Each reaction included $2 \mu \mathrm{L}$ of DNA template ( $10 \mathrm{ng}$ per $\mu \mathrm{L})$. The assay was performed three times against each isolate.

\section{Detection of $\boldsymbol{P}$. hibernalis in artificially inoculated orange fruits using RPA-LFD}

Prior to inoculation, orange fruits (Citrus sinensis) were washed in distilled water, immersed in $70 \%$ ethanol for $10 \mathrm{sec}$, and then rinsed with distilled water. Each fruit was wounded (approximately $2 \mathrm{~cm}$ depth) using a sterile inoculation needle. A 5-day-old cV8A plug $(1 \times 1 \mathrm{~cm})$ of $P$. hibernalis isolate 9099 was placed onto the wound site of each of six replicate fruits and secured with parafilm. A sterile cV8A plug was used on a non-inoculated control fruit. 
161 All fruits were then placed on two layers of wet filter papers in a container and stored in a dark 162 incubator set at $20^{\circ} \mathrm{C}$. After four days, symptoms resembling those of brown rot were observed 163 around the wound sites of inoculated fruits. Fruits were rinsed with distilled water to remove the 164 remaining agar plugs. Both flesh and peel tissues around the wound site were cut into approximately $1 \times 1-\mathrm{cm}$ pieces, and placed onto PARP-cV8A selective media (Jeffers \& Martin 1986) to recover Phytophthora isolates at $20^{\circ} \mathrm{C}$. Total DNAs of these tissues were extracted using a previously described $\mathrm{NaOH}$ method (Wang et al. 1993). Briefly, $20 \mathrm{mg}$ of plant tissues collected from the wound site of each fruit were placed into a 1.5-mL microtube containing 200 $\mu \mathrm{L}$ of $\mathrm{NaOH}(0.5 \mathrm{~N})$. They were grinded for approximately 1 min until no large pieces of plant tissues were visible using a sterile tissue grinder pestle. Then, $5 \mu \mathrm{L}$ of grinded tissues in $\mathrm{NaOH}$ were transferred to a new microtube containing $495 \mu \mathrm{L}$ of Tris buffer (100 mM, pH 8.0). Two ng per $\mu \mathrm{L}$ ) and $\mathrm{nfH}_{2} \mathrm{O}$ were used as a positive control and NTC, respectively. This experiment was repeated once.

\section{Results}

177

\section{Optimal duration of RPA}

RPA was performed using isolate 9099 gDNA (10 ng per $\mu \mathrm{L})$ for different amplification durations ranging from 5 to 30 min with 5-min intervals. Both test and control lines were visible on all dipsticks in three repeats of the experiment. Whereas the test lines correlated to 5-min RPA were weak, as the amplification extended to $10 \mathrm{~min}$ and longer, they increased in intensity (Fig. 1). Based on the finding, the amplification duration was set at $20 \mathrm{~min}$ for the subsequent RPA reactions. 
184

185

186

187

188

\section{Sensitivity and specificity of the RPA-LFD assay}

In the sensitivity evaluation of the RPA-LFD assay, all dipsticks yielded visible control lines, indicating valid tests. Test lines were visible on all dipsticks correlating to RPA reactions using $\geq 0.2 \mathrm{ng}(2 \mu \mathrm{L}, 0.1 \mathrm{ng}$ per $\mu \mathrm{L})$ gDNA of $P$. hibernalis isolate 9099 (Fig. 2A). No test lines were observed on dipsticks using $\leq 0.02 \mathrm{ng}$ of gDNA (Fig. 2A). In the comparative evaluation of the PCR assay, $\geq 2$ ng of gDNA was required in each PCR reaction for the successful amplification using primers PhRPA-F and PhRPA-R (Fig. 2B). The above results were consistent among three repeats of each assay.

In the specificity evaluation of the RPA-LFD assay, all LFDs had visible control lines. Only the reactions using gDNAs of $P$. hibernalis isolates yielded positive detection results (Table 2). The results were consistent among three repeats of the experiment against each isolate.

\section{Detection of $P$. hibernalis in artificially inoculated orange fruits using RPA-LFD}

In the first repeat of the experiment, $P$. hibernalis isolates were recovered from all six inoculated orange fruits, which had shown typical brown rot symptoms at the wounded sites four days after inoculation, while not from the non-inoculated control fruit. In the RPA-LFD assay, $P$. hibernalis DNAs were detected in total DNAs extracted from six artificially inoculated fruits, while the non-inoculated control lacked detection of $P$. hibernalis (Fig. 3). In the second repeat experiment, only three of six inoculated fruits had shown brown rot symptoms after four days, while the other three as well as the non-inoculated control remained asymptomatic.

Correspondingly, total DNAs of three symptomatic fruits yielded positive detection of $P$. hibernalis in the RPA-LFD assay, whereas the remaining fruits gave rise to negative results (Fig. 3).

\section{Discussion}


A novel RPA-LFD assay for detecting $P$. hibernalis, the quarantine citrus pathogen in

208 China, was developed in this study. This assay consistently detected $0.2 \mathrm{ng}$ of P. hibernalis genomic DNA in a 50- $\mu \mathrm{L}$ RPA reaction (4 pg per $\mu \mathrm{L}$ in the reaction). It also was demonstrated as specific to $P$. hibernalis, while yielded no detection against 43 isolates belonging to 38 non- $P$. hibernalis species. Furthermore, this assay was able to detect $P$. hibernalis from artificially inoculated orange fruits, indicating its potential application on field samples. requires much shorter time span of 15 to $35 \mathrm{~min}$, including 10 to $30 \mathrm{~min}$ for the RPA step (Fig. 1) and 5 min for the visualization of detection results using LFDs, whereas a typical 30-cycles PCR requires approximately $90 \mathrm{~min}$. Second, RPA in this study was carried out at a constant temperature of $38^{\circ} \mathrm{C}$, while this amplification step theoretically could be done within a wider temperature range of 25 to $45^{\circ} \mathrm{C}$ (Daher et al. 2016; James \& Macdonald 2015). The visualization step using LFDs was performed at room temperature (aver. $22^{\circ} \mathrm{C}$ ). In contrast, PCR-based methods require thermocyclers for stringent temperature control. Third, the results of RPA could be visualized on LFDs promptly with naked eyes (Fig. 2A), while examining PCR results typically required gel electrophoresis and fluorometers (Fig. 2B).

This novel RPA-LFD assay has great potentials of use for specific detection of $P$. hibernalis on citrus fruits. As demonstrated in this study, this assay was able to detect $P$. hibernalis using total DNA of $P$. hibernalis-infected fruits (Fig. 3), while lacked detection against any other tested species (Table 2) including four other important Phytophthora species that are pathogens of citrus crops, namely $P$. citrophthora, $P$. nicotianae, $P$. palmivora, and $P$. syringae. Such specificity in conjunction with its high sensitivity make this assay an ideal primary screening tool for detecting P. hibernalis in diagnostic laboratories and plant quarantine departments at customs. 
232 in this study could be performed within $25 \mathrm{~min}$. We also implemented a modified $\mathrm{NaOH}$ method

233 for extracting RPA-ready DNAs from $P$. hibernalis-infected fruits within 5 min. Such short time span and low requirement for special equipment and operation skills allow first responders and diagnosticians process a large quantity of samples under time- and resource-limited conditions.

Different rapid DNA extraction methods have been used for other RPA assays detecting Phytophthora species. For example, Miles et al. (2015) tested six crude extraction buffers using

Fragaria $\times$ ananassa crown tissues and P. cactorum DNA, and subsequently chose the GEB2 buffer (ACC 00130, Agdia, Elkhart, Indiana, USA) to rapidly prepare DNA samples for a Phytophthora genus-specific RPA assay. Yu et al. (2019) used a cellulose dipstick method to obtain amplification-ready DNA for an RPA-LFD assay detecting $P$. capsici. It will be meaningful to evaluate these extraction media against various host tissues and compare their influence on the efficacy of RPA assays in future studies.

While saving time, the RPA-LFD assay is comparable to PCR in cost-effectiveness. Estimated costs for processing 10 samples at customs in Jiangsu and Shanghai, China are similar between using RPA-LFD and PCR (Table 3). The RPA-LFD assay has the advantage in reducing labor costs and avoiding both direct and indirect costs associated with special equipment such as thermal cycler and gel electrophoresis system (Table 3). While the materials of RPA-LFD including the TwistAmp ${ }^{\circledR}$ nfo reaction reagents and HybriDetect 1 Lateral Flow Dipsticks are currently more costly than those of PCR (Table 3), shorter diagnostic time at the customs reduces berthing fees for shipping companies, conserves important shelf life of fresh products such as fruits 
252 and vegetables, and subsequently reduces prices for customers. The extract cost-effectiveness of

253 RPA assays for the diagnosis of quarantine plant pathogens warrants more detailed evaluations.

\section{Competing Interests}

The authors declare there are no competing interests.

\section{Acknowledgements}

257

258

259

260

261

262

263

264

265

266

267

268

269

270

271

This work was supported by the National Natural Science Foundation of China (31500526), China Postdoctoral Science Foundation (2016T790467), Overseas Research and Study Project of Excellent Young and Middle-aged Teachers and Principals in Colleges and Universities of Jiangsu Province of 2018, the Priority Academic Program Development of Jiangsu Higher Education Institutions, the General Program of Jiangsu Science and Technology Department (SBK 2019021775), Special Fund for Agro-scientific Research in the Public Interest (201503112), Jiangsu Basic Research Program (Natural Science Foundation) Project (BK 20191389), and Jiangsu University Natural Science Research Surface Project (19KJB220003).

Mention of trade names or commercial products in this publication is solely for the purpose of providing specific information and does not imply recommendation or endorsement by the U.S. Department of Agriculture. USDA is an equal opportunity provider and employer.

\section{References}

Adaskaveg JE, and Förster H. 2014. Integrated postharvest strategies formanagement of Phytophthora brown rot of citrus in the United States. In: Prusky D, and Gullino ML, eds. 
Post-harvest Pathology: Plant Pathology in the 21st Century, Contributions to the 10th International Congress, ICPP 2013. Cham, Switzerland: Springer International Publishing, 123-131.

Benson DA, Cavanaugh M, Clark K, Karsch-Mizrachi I, Ostell J, Pruitt KD, and Sayers EW. 2018. GenBank. Nucleic Acids Res 46:D41-D47. 10.1093/nar/gkx1094

Daher RK, Stewart G, Boissinot M, and Bergeron MG. 2016. Recombinase polymerase amplification for diagnostic applications. Clinical Chemistry 62:947-958. 10.1373/clinchem.2015.245829

Dai TT, Lu CC, Lu J, Dong SM, Ye WW, Wang YC, and Zheng XB. 2012. Development of a loop-mediated isothermal amplification assay for detection of Phytophthora sojae. FEMS Microbiol Lett 334:27-34. 10.1111/j.1574-6968.2012.02619.x

Dai TT, Yang X, Hu T, Li ZY, Xu Y, and Lu CC. 2019. A novel LAMP assay for the detection of Phytophthora cinnamomi utilizing a new target gene identified from genome sequences. Plant Dis In Press.

Dai TT, Zheng XB, and Wu XQ. 2015. LAMP assay for rapid detection of Phytophthora sojae based on its Ypt1 gene. Acta Phytopathologica Sinica 6:576-584.

Erwin DC, and Ribeiro OK. 1996. Phytophthora diseases worldwide. St. Paul, Minnesota, USA: APS Press.

Ghosh DK, Kokane SB, Kokane AD, Warghane AJ, Motghare MR, Bhose S, Sharma AK, and Reddy MK. 2018. Development of a recombinase polymerase based isothermal amplification combined with lateral flow assay (HLB-RPA-LFA) for rapid detection of "Candidatus Liberibacter asiaticus". PLoS ONE 13. 10.1371/journal.pone.0208530

Graham JH, and Menge JA. 2000. Phytophthora-induced diseases. In: Timmer LW, Garnsey 
295

296

297

298

299

300

301

302

303

304

305

306

307

308

309

310

311

312

313

314

315

316

317

SM, and Graham JH, eds. Compendium of Citrus Diseases. 2nd ed. St. Paul, MN: APS Press, 12-15.

Hansen ZR, Knaus BJ, Tabima JF, Press CM, Judelson HS, Grünwald NJ, and Smart CD. 2016. Loop-mediated isothermal amplification for detection of the tomato and potato late blight pathogen, Phytophthora infestans. J Appl Microbiol 120:1010-1020. 10.1111/jam.13079

Hao W, Miles TD, Martin FN, Browne GT, Forster HF, and Adaskaveg JE. 2018. Temporal occurrence and niche preferences of Phytophthora spp. causing brown rot of citrus in the Central Valley of California. Phytopathology 108:384-391. 10.1094/phyto-09-17-0315-r

Hou PL, Zhao GM, Wang HM, He CQ, Huan YJ, and He HB. 2018. Development of a recombinase polymerase amplification combined with lateral-flow dipstick assay for detection of bovine ephemeral fever virus. Molecular and Cellular Probes 38:31-37. 10.1016/j.mcp.2017.12.003

James A, and Macdonald J. 2015. Recombinase polymerase amplification: Emergence as a critical molecular technology for rapid, low-resource diagnostics. Expert Review of Molecular Diagnostics 15:1475-1489. 10.1586/14737159.2015.1090877

Jeffers SN, and Martin SB. 1986. Comparison of two media selective for Phytophthora and Pythium species. Plant Dis 70:1038-1043.

Jiao B, Liu J, Song S, Chen Z, Yu C, and Yi J. 2017. Isolation and identification of Phytophthora hibernalis from the Californian Citrus grandis fruit. Acta Phytopathologica Sinica 47:433-439. DOI: 10.13926/j.cnki.apps.000025

Khan M, Li B, Jiang Y, Weng Q, and Chen Q. 2017. Evaluation of different PCR-based assays and LAMP method for rapid detection of Phytophthora infestans by targeting the Ypt1 gene. Front Microbiol 8:1920. 10.3389/fmicb.2017.01920 
318 Larkin MA, Blackshields G, Brown NP, Chenna R, McGettigan PA, McWilliam H, Valentin F,

319 Wallace IM, Wilm A, Lopez R, Thompson JD, Gibson TJ, and Higgins DG. 2007.

320 Clustal W and Clustal X version 2.0. Bioinformatics 23:2947-2948.

321 10.1093/bioinformatics/btm404

322

Li BJ, Liu PQ, Xie SY, Yin RM, Weng QY, and Chen QH. 2015. Specific and sensitive detection of Phytophthora nicotianae by nested PCR and loop-mediated isothermal amplification assays. Journal of Phytopathology 163:185-193. doi: 10.1111/jph.12305

Li GR, Huang GM, Zhu LH, Lv DJ, Cao BH, Liao F, and Luo JF. 2019. Loop-mediated isothermal amplification (LAMP) detection of Phytophthora hibernalis, P. syringae and P. cambivora. Journal of Plant Pathology 101:51-57. 10.1007/s42161-018-0136-5

Martin FN, Blair JE, and Coffey MD. 2014. A combined mitochondrial and nuclear multilocus phylogeny of the genus Phytophthora. Fungal Genetics and Biology 66:19-32. 10.1016/j.fgb.2014.02.006

Miles TD, Martin FN, and Coffey MD. 2015. Development of rapid isothermal amplification assays for detection of Phytophthora spp. in plant tissue. Phytopathology 105:265-278. 10.1094/phyto-05-14-0134-r

Notomi T, Okayama H, Masubuchi H, Yonekawa T, Watanabe K, Amino N, and Hase T. 2000. Loop-mediated isothermal amplification of DNA. Nucleic Acids Res 28:E63.

Piepenburg O, Williams CH, Stemple DL, and Armes NA. 2006. DNA detection using recombination proteins. PLoS Biology 4:1115-1121. 10.1371/journal.pbio.0040204

Rojas JA, Miles TD, Coffey MD, Martin FN, and Chilvers MI. 2017. Development and application of qPCR and RPA genus- and species-specific detection of Phytophthora sojae and P. sansomeana root rot pathogens of soybean. Plant Dis 101:1171-1181. 
341

342

343

344

345

346

347

348

349

350

351

352

353

354

355

356

10.1094/pdis-09-16-1225-re

Schlatter RP, Matte U, Polanczyk CA, Koehler-Santos P, and Ashton-Prolla P. 2015. Costs of genetic testing: Supporting Brazilian Public Policies for the incorporating of molecular diagnostic technologies. Genetics and Molecular Biology 38:332-337. 10.1590/s1415475738320140204

Si Ammour M, Bilodeau GJ, Tremblay DM, Van der Heyden H, Yaseen T, Varvaro L, and Carisse O. 2017. Development of real-time isothermal amplification assays for on-site detection of Phytophthora infestans in potato leaves. Plant Dis 101:1269-1277. 10.1094/pdis-12-16-1780-re

Wang H, Qi M, and Cutler AJ. 1993. A simple method of preparing plant samples for PCR. Nucleic Acids Res 21:4153-4154.

Yang X, Tyler BM, and Hong CX. 2017. An expanded phylogeny for the genus Phytophthora. IMA Fungus 8:355-384. 10.5598/imafungus.2017.08.02.09

Yu J, Shen D, Dai T, Lu X, Xu H, and Dou D. 2019. Rapid and equipment-free detection of Phytophthora capsici using lateral flow strip-based recombinase polymerase amplification assay. Letters in Applied Microbiology 69:64-70. 10.1111/lam.13166 


\section{Figure captions}

358 Fig.1 Detection of the genomic DNA (10 ng per $\mu \mathrm{L})$ of Phytophthora hibernalis isolate 9099 using 359 the recombinase polymerase amplification-lateral flow dipstick (RPA-LFD) assay with various 360 amplification durations ranging from 5 to 30 min with 5-min intervals

Fig. 2 Sensitivity of the recombinase polymerase amplification-lateral flow dipstick (A) and PCR

(B) assays using 10-fold dilutions of genomic DNA (gDNA; ng per $\mu \mathrm{L}$ ) of Phytophthora

364

365

366

367

368

369

370

371

372

373

374

375

376

377 hibernalis isolate 9099 . Two $\mu \mathrm{L}$ of gDNA were added to each $50-\mu \mathrm{L}$ reaction. Nuclease-free water was used in no-template controls (NTC). M: NormalRun ${ }^{\mathrm{TM}}$ prestained 250bp-I DNA ladder (GsDL2501; Generay Biotech, Shanghai, China).

Fig. 3 Detection of Phytophthora hibernalis in artificially inoculated orange fruits using the recombinase polymerase amplification-lateral flow dipstick assay. Positive control: genomic DNA (10 ng per $\mu \mathrm{L}$ ) of $P$. hibernalis isolate 9099; 1-6: inoculated, symptomatic fruits in the first repeat experiment; 7-9: inoculated, symptomatic fruits in the second repeat; 10-12: inoculated, asymptomatic fruits in the second repeat; Negative control: non-inoculated fruits.

Fig. S1 Multiple sequence alignment of the Ypt1 gene of Phytophthora hibernalis and other species. Alignment was carried out using Clustal W. Nucleotides targeted by PhRPA-F, PhRPA$\mathrm{R}$, and $\mathrm{PhProbe}$ in the recombinase polymerase amplification-lateral flow dipstick assay are above respective lines. 


\section{Table $\mathbf{1}$ (on next page)}

List of isolates used in the study and their detection results in the recombinase polymerase amplification-lateral flow dipstick (RPA-LFD) assay 
1 Table 1 List of isolates used in the study and their detection results in the recombinase polymerase amplification-lateral flow dipstick

2 (RPA-LFD) assay

\begin{tabular}{|c|c|c|c|c|c|}
\hline (Sub)clade ${ }^{\mathrm{a}}$ & Species & Isolate & Host/substrate & Location $^{\mathrm{b}}$ & RPA-LFD ${ }^{c}$ \\
\hline \multirow[t]{4}{*}{$8 \mathrm{c}$} & Phytophthora hibernalis & 9099 & Citrus grandis & SH, China & + \\
\hline & P. hibernalis & CBS 270.31 & Citrus sinensis & Setúbal, Portugal & + \\
\hline & P. lateralis & CBS 168.42 & Chamaecyparis lawsoniana & Oregon, USA & - \\
\hline & P. ramorum & EU1 2275 & Laurus nobilis & United Kingdom & - \\
\hline \multirow[t]{4}{*}{$8 \mathrm{a}$} & P. cryptogea & Pcr1 & Gerbera jamesonii & JS, China & - \\
\hline & P. drechsleri & CBS 292.35 & Beta vulgaris var. altissima & California, USA & - \\
\hline & P. erythroseptica & CBS 129.23 & Solanum tuberosum & Ireland & - \\
\hline & P. medicaginis & ATCC 44390 & Medicago sativa & California, USA & - \\
\hline $8 \mathrm{~b}$ & P. brassicae & CBS 178.87 & Brassica sp. & Germany & - \\
\hline \multirow[t]{2}{*}{$8 \mathrm{~d}$} & P. syringae & 947 & Malus domestica & SH, China & - \\
\hline & P. syringae & CBS 132.23 & Malus domestica & United Kingdom & - \\
\hline \multirow[t]{4}{*}{1} & P. cactorum & Pcac2 & Rosa chinensis & FJ, China & - \\
\hline & P. infestans & Pin 1 & Solanum tuberosum & FJ, China & - \\
\hline & P. nicotianae & Pni1 & Nicotiana tabacum & YN, China & - \\
\hline & P. tentaculata & Pte1 & Saussurea costus & YN, China & - \\
\hline \multirow[t]{2}{*}{2} & P. capsici & Pcap1 & Capsicum annuum & JS, China & - \\
\hline & P. citrophthora & Pcitro1 & Citrus reticulata & JS, China & - \\
\hline \multirow[t]{2}{*}{4} & P. palmivora & Ppa1 & Iridaceae sp. & YN, China & - \\
\hline & P. quercina & CBS 789.95 & Rhizosphere of Quercus cerris & Germany & - \\
\hline 6 & P. megasperma & CBS 305.36 & Matthiola incana & California, USA & - \\
\hline \multirow[t]{8}{*}{7} & P. cinnamomi & Pcin 1 & Cedrus deodara & JS, China & - \\
\hline & P. melonis & Pmel (PMNJHG1) & Cucumis sativus & JS, China & - \\
\hline & P. rubi & CBS 967.95 & Rubus idaeus & Scotland, UK & - \\
\hline & P. sojae & P6497 & Glycine max & Mississippi, USA & - \\
\hline & P. sojae & Peng-R3 & Glycine $\max$ & China & - \\
\hline & P. sojae & Peng-R20 & Glycine $\max$ & China & - \\
\hline & P. $\times$ cambivora & CBS 248.60 & Castanea sativa & France & - \\
\hline & P. $\times$ cambivora & Pcam1 & Malus domestica & SH, China & - \\
\hline 10 & P. boehmeriae & Pbol & Gossypium sp. & JS, China & - \\
\hline
\end{tabular}




\begin{tabular}{|c|c|c|c|c|c|}
\hline Globisporangium & Globisporangium ultimum & Gu1 & Irrigation water & JS, China & - \\
\hline \multirow[t]{15}{*}{ Fungi } & Alternaria alternata & Aall & Soil & JS, China & - \\
\hline & Botrytis cinerea & Bcil & Cucumis sativus & JS, China & - \\
\hline & Bremia lactucae & Bla1 & Lactuca sativa & JS, China & - \\
\hline & Colletotrichum glycines & Cgl1 & Glycine $\max$ & JS, China & - \\
\hline & C. orbiculare & Cor 1 & Citrullus lanatus & JS, China & - \\
\hline & C. truncatum & Ctr1 & Glycine $\max$ & JS, China & - \\
\hline & Endothia parasitica & Epa1 & Castanea mollissima & JS, China & - \\
\hline & Fusarium equiseti & Feq1 & Gossypium sp. & JS, China & - \\
\hline & F. oxysporium & Fox 1 & Gossypium sp. & JS, China & - \\
\hline & F. solani & Fsol & Gossypium sp. & JS, China & - \\
\hline & F. solani & Fso2 & Glycine $\max$ & JS, China & - \\
\hline & Magnaporthe grisea & Guy11 & Oryza sativa & French Guiana & - \\
\hline & Rhizoctonia solani & Rso1 & Gossypium sp. & JS, China & - \\
\hline & Tilletia indica & Tin 1 & Triticum aestivum & JS, China & - \\
\hline & Verticillium dahliae & Vda1 & Gossypium sp. & JS, China & - \\
\hline
\end{tabular}

3 a Molecular phylogenetic (sub)clade of Phytophthora species as indicated by Martin et al. (2014) and Yang et al. (2017)

$4 \quad{ }^{b}$ Abbreviations of provinces and municipality in China: $\mathrm{SH}=$ Shanghai; JS = Jiangsu; FJ = Fujian; YN = Yunnan

$5 \quad{ }^{\mathrm{c}}$ Positive (+) or negative (-) detection result in the RPA-LFD assay for detecting P. hibernalis 


\section{Table 2 (on next page)}

Oligonucleotide primers and probe designed for the recombinase polymerase amplification-lateral flow dipstick assay 
1 Table 2 Oligonucleotide primers and probe designed for the recombinase polymerase amplification-lateral flow dipstick assay

\begin{tabular}{llcc}
\hline Name & Sequence (5'-3') & Length (mer) & GC-content (\%) \\
\hline PhRPA-F primer & TTCCACCCTTCCACCAGACTGCTGAGGAGG & 30 & 60.0 \\
PhRPA-R primer & Biotin-TGTTAGCTGCGTGTTCGTTGGTCACCCCAGA & 31 & 54.8 \\
PhProbe & FAM- & & 45.8 \\
& CTTCTGTGATTTATCCAGAAAATCCGTACGAT- & 48 & \\
& THF-GAGCTGGACGGCAAGA-C3 space & &
\end{tabular}




\section{Table 3(on next page)}

Comparison of estimated costs of the recombinase polymerase amplification-lateral flow dipstick (RPA-LFD) assay and conventional PCR for processing 10 samples 
conventional PCR for processing 10 samples

\begin{tabular}{|c|c|c|c|c|c|}
\hline \multirow[b]{2}{*}{ Material } & \multirow[b]{2}{*}{ Cost (US \$) / unit } & \multicolumn{2}{|c|}{ RPA-LFD } & \multicolumn{2}{|c|}{ PCR } \\
\hline & & Amount & Cost & Amount & Cost \\
\hline Labor & $15 /$ hour $^{\mathrm{a}}$ & 0.5 & 7.5 & 3 & 45 \\
\hline Gloves & $0.1 /$ pair & 1 & 0.1 & 1 & 0.1 \\
\hline Pipette tips $(0-200 \mu \mathrm{L})$ & 0.03 each & 10 & 0.3 & 10 & 0.3 \\
\hline Pipette tips $(0-10 \mu \mathrm{L})$ & 0.03 each & 10 & 0.3 & 30 & 0.9 \\
\hline Microtubes $1.5 \mathrm{~mL}$ & 0.02 each & 22 & 0.44 & 1 & 0.02 \\
\hline Microtubes $0.2 \mathrm{~mL}$ & 0.03 each & $\mathrm{n} / \mathrm{a}^{\mathrm{b}}$ & $\mathrm{n} / \mathrm{a}$ & 10 & 0.3 \\
\hline TwistAmp® nfo reaction & $3.13 \mathrm{each}^{\mathrm{c}}$ & 10 & 31.3 & $\mathrm{n} / \mathrm{a}$ & $\mathrm{n} / \mathrm{a}$ \\
\hline HybriDetect 1 Lateral Flow Dipstick & $2.75 \mathrm{each}^{\mathrm{d}}$ & 10 & 27.5 & $\mathrm{n} / \mathrm{a}$ & $\mathrm{n} / \mathrm{a}$ \\
\hline $2 \times$ Taq Master Mix & $0.006 / \mu \mathrm{L}$ & $\mathrm{n} / \mathrm{a}$ & $\mathrm{n} / \mathrm{a}$ & 250 & 1.5 \\
\hline Forward oligonucleotide $(10 \mu \mathrm{M})$ & $0.15 / \mu \mathrm{L}$ & 21 & 3.15 & 20 & 3 \\
\hline Reverse oligonucleotide $(10 \mu \mathrm{M})$ & $0.15 / \mu \mathrm{L}$ & 21 & 3.15 & 20 & 3 \\
\hline Oligonucleotide probe $(10 \mu \mathrm{M})$ & $0.5 / \mu \mathrm{L}$ & 6 & 3 & $\mathrm{n} / \mathrm{a}$ & $\mathrm{n} / \mathrm{a}$ \\
\hline Electrophoresis & 0.6 / sample & $\mathrm{n} / \mathrm{a}$ & $\mathrm{n} / \mathrm{a}$ & 10 & 6 \\
\hline Gel staining and imaging & 0.2 / sample & $\mathrm{n} / \mathrm{a}$ & $\mathrm{n} / \mathrm{a}$ & 10 & 2 \\
\hline Losses $(10 \%)^{\mathrm{e}}$ & & & 7.67 & & 6.21 \\
\hline Indirect $\operatorname{costs}{ }^{f}$ & & & 3 & & 18 \\
\hline Total for 10 samples & & & 87.41 & & 86.33 \\
\hline
\end{tabular}

${ }^{\mathrm{b}} \mathrm{n} / \mathrm{a}=$ not applicable

${ }^{c}$ Each TwistAmp ${ }^{\circledR}$ nfo Kit (£240) includes 96 reactions.

${ }^{\mathrm{d}}$ Milenia HybriDetect 1 (pack of 100) costs $£ 220$.

e Ten percent on the total amount of direct costs was defined a priori, the losses of consumables that occur during the execution of techniques (Schlatter et al. 2015).

${ }^{\mathrm{f}}$ Approximate indirect costs of facility security and maintenance, purchase and maintenance of special equipment such as thermal cycler,

gel electrophoresis system, and transilluminator, and electricity 
Figure 1

Detection of the genomic DNA (10 ng per $\mu \mathrm{L}$ ) of Phytophthora hibernalis isolate 9099 using the recombinase polymerase amplification-lateral flow dipstick (RPA-LFD) assay with various amplification durations ranging from 5 to 30 min with 5-min interva 


\section{Duration (min) of RPA}

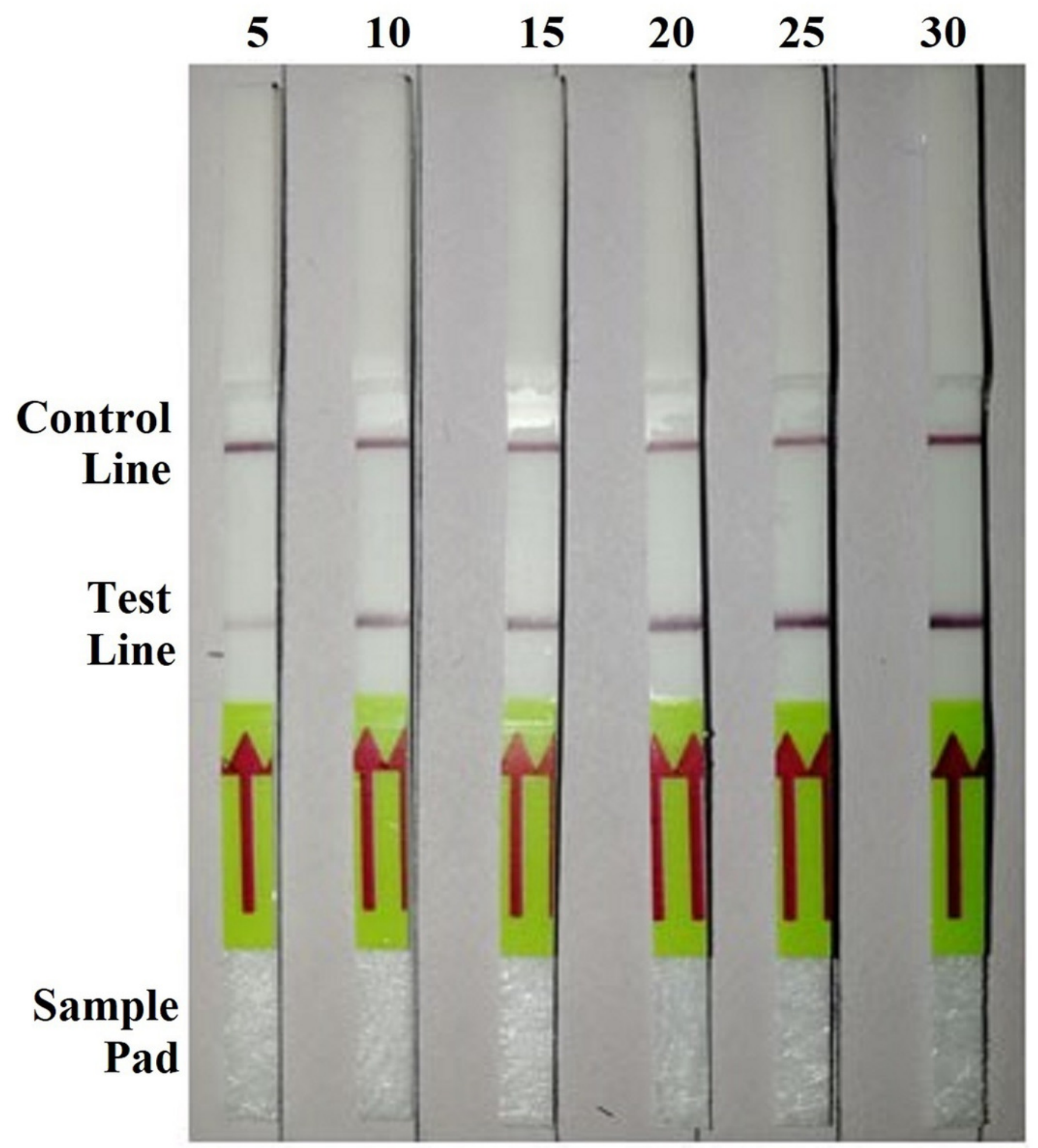


Figure 2

Sensitivity of the recombinase polymerase amplification-lateral flow dipstick (A) and PCR (B) assays using 10-fold dilutions of genomic DNA (gDNA; ng per $\mu \mathrm{L}$ ) of Phytophthora hibernalis isolate 9099.

Two $\mu \mathrm{L}$ of gDNA were added to each $50-\mu \mathrm{L}$ reaction. Nuclease-free water was used in notemplate controls (NTC). M: NormalRun ${ }^{\mathrm{TM}}$ prestained 250bp-I DNA ladder (GsDL2501; Generay Biotech, Shanghai, China). 
(A)

gDNA (ng per $\mu \mathrm{L})$ / reaction

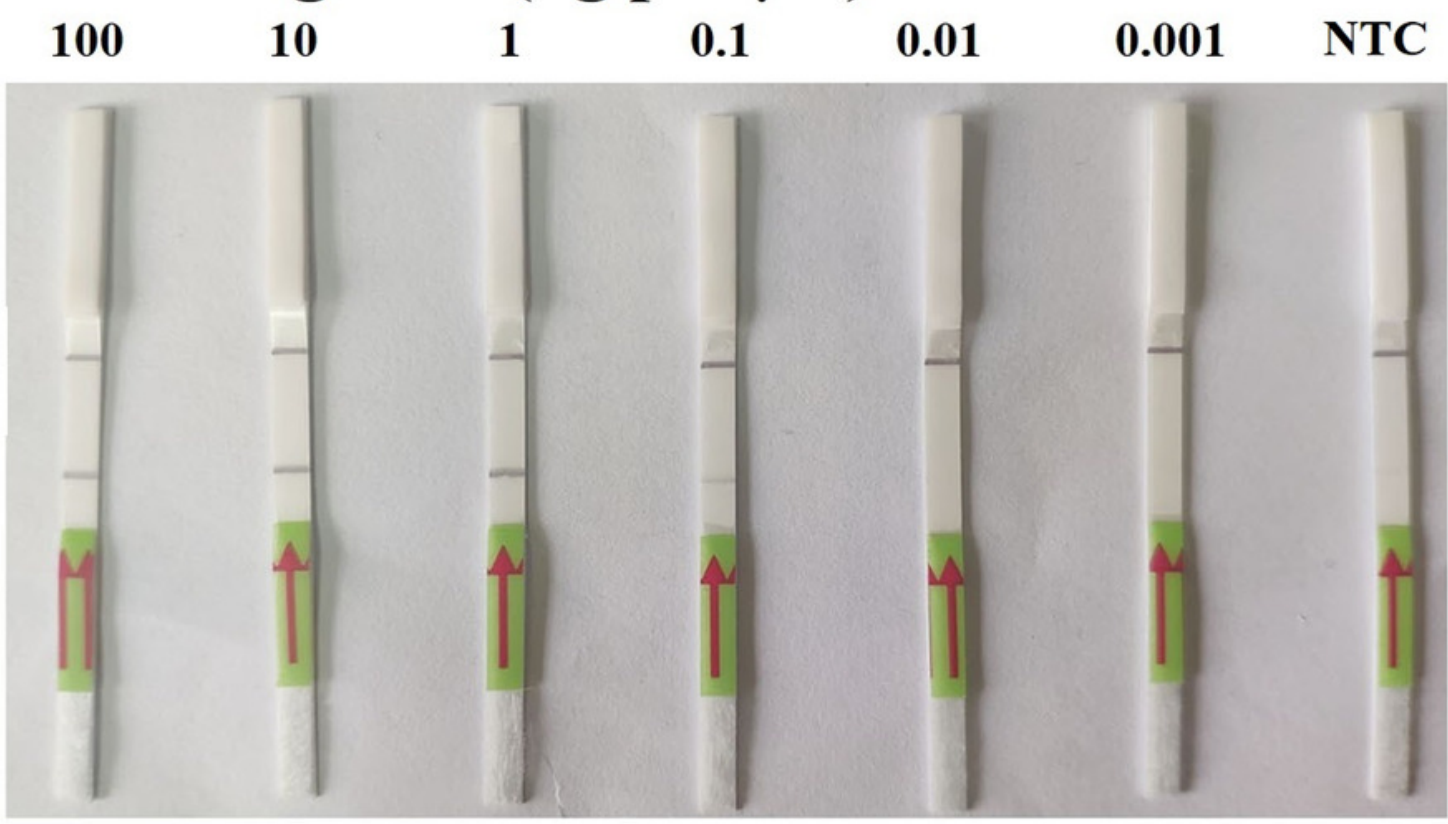

(B)

\section{gDNA (ng per $\mu \mathrm{L}$ ) / reaction \\ $\begin{array}{llllllll}M & 100 & 10 & 1 & 0.1 & 0.01 & 0.001 & \text { NTC }\end{array}$}

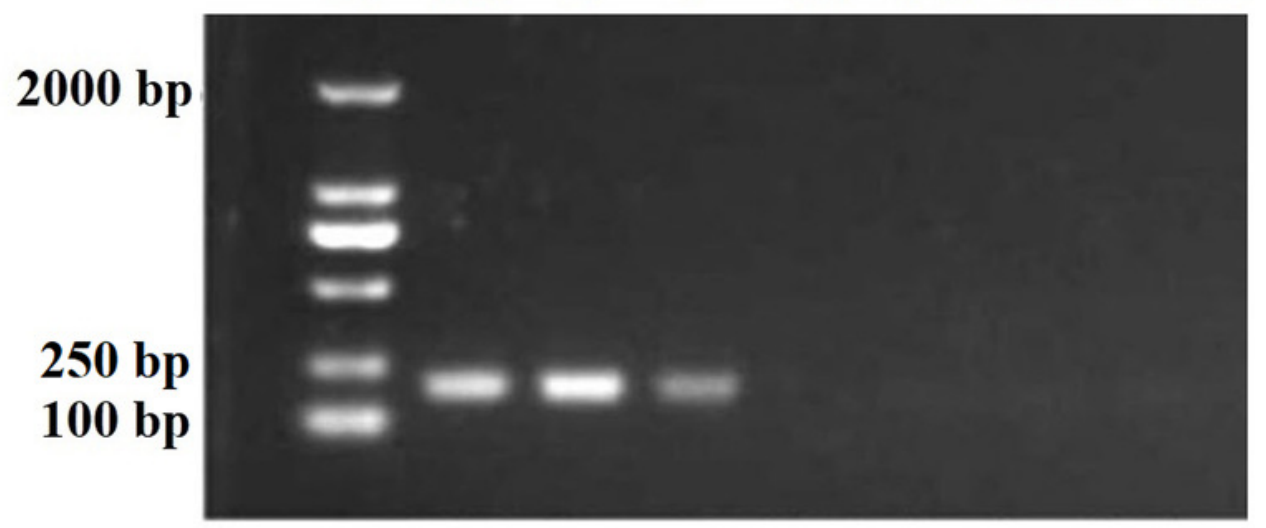




\section{Figure 3}

Detection of Phytophthora hibernalis in artificially inoculated orange fruits using the recombinase polymerase amplification-lateral flow dipstick assay.

Positive control: genomic DNA (10 ng per $\mu \mathrm{L}$ ) of $P$. hibernalis isolate $9099 ; 1-6$ : inoculated, symptomatic fruits in the first repeat experiment; 7-9: inoculated, symptomatic fruits in the second repeat; 10-12: inoculated, asymptomatic fruits in the second repeat; Negative control: non-inoculated fruits.

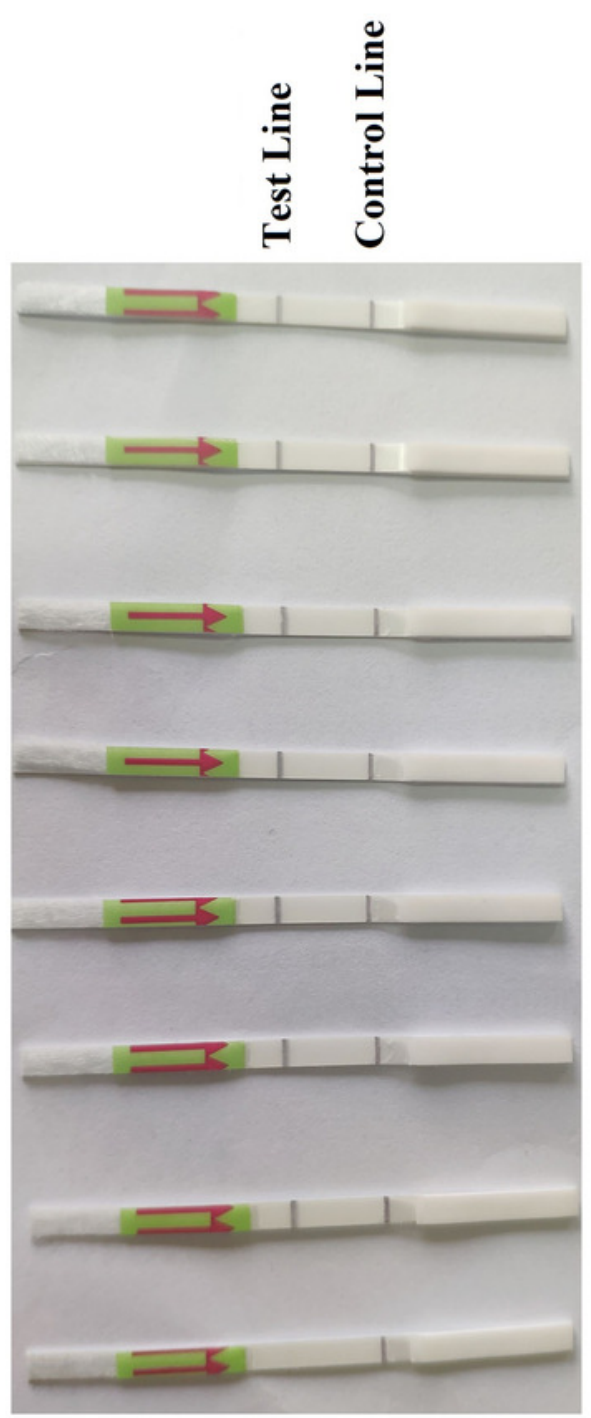

Positive control

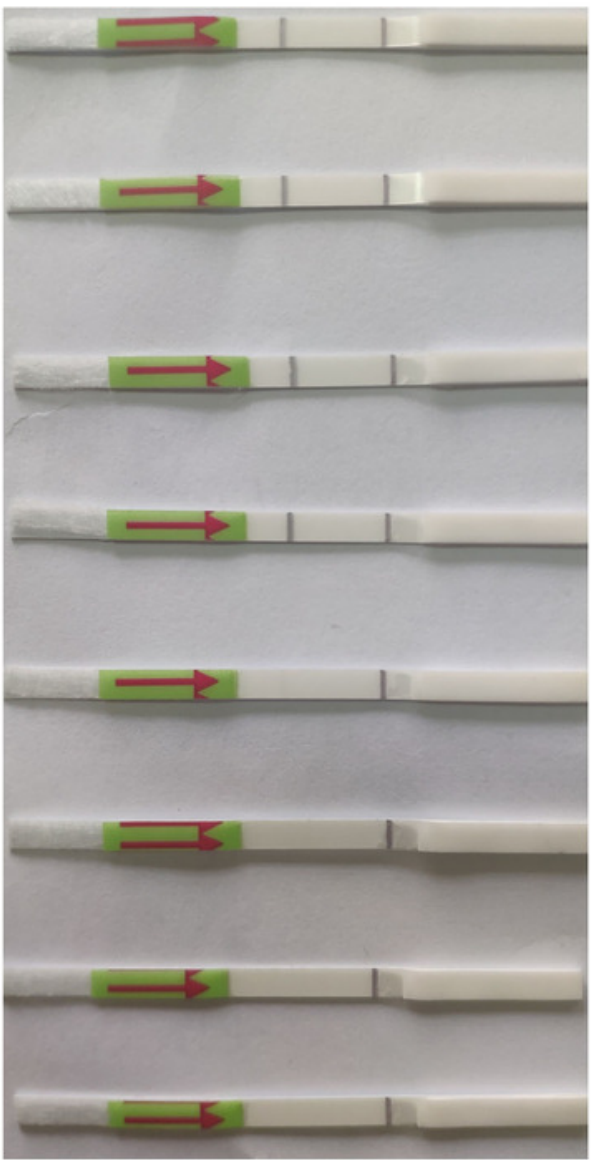

Positive control

7

8

9

10

11

12

Negative control 